\title{
Thermogenic and hemodynamic effects of ingesting a pre-workout supplement with and without synephrine
}

\author{
YP Jung, C Goodenough, M Cho, A O'Connor, R Dalton, K Levers, E Galvan, N Barringer, F Ayadi, J Carter, \\ M Koozechian, S Simbo, A Reyes, B Sanchez, A Coletta, C Rasmussen, R Kreider
}

From The Eleventh International Society of Sports Nutrition (ISSN) Conference and Expo

Clearwater Beach, FL, USA. 20-21 June 2014

\section{Background}

A number of nutritional strategies have been developed to optimize nutrient delivery prior to exercise. As a result, a number of pre-workout supplements have been developed to increase energy availability, promote vasodilation, and/ or positively affect exercise capacity. The purpose of this study was to examine the acute effects of ingesting a preworkout dietary supplement with and without synephrine on energy metabolism and cardiovascular hemodynamics.

\section{Methods}

In a double-blind, crossover, randomized and placebocontrolled manner; 25 apparently healthy and recreationally active men and women $(21.76 \pm 3.00 \mathrm{yr}, 15.24 \pm 5.26 \%$ fat, $25.09 \pm 3.03 \mathrm{~kg} / \mathrm{m} 2$ ) volunteered to participate in this study and had resting blood pressure (BP), heart rate (HR), 12-lead electrocardiographs (ECG), and resting energy expenditure (REE) measured for 10 minutes. Participants then ingested in a randomized and counterbalanced manner a dextrose flavored placebo $(\mathrm{P})$; a preworkout supplement (PWS) containing $3.0 \mathrm{~g}$ beta alanine, $2 \mathrm{~g}$ creatine nitrate, $2 \mathrm{~g}$ arginine AKG, $300 \mathrm{mg}$ of $\mathrm{N}$-acetyl tyrosine, $270 \mathrm{mg}$ caffeine, $15 \mathrm{mg}$ of Mucuna pruriens; or, the PWS with $20 \mathrm{mg}$ of synephrine (PWS+S). Metabolic changes were measured continuously while BP, HR, and ECG's were obtained every 10 minutes during the REE test. Participants repeated the experiment after a one week washout period with the alternate supplements in a randomized and counterbalanced manner. Data were analyzed by repeated measure MANOVA and are presented as means \pm SD or SEM from baseline. Consent to publish the results was obtained from all participants.

\section{Results}

MANOVA analysis revealed a significant overall Wilks' Lambda time $(\mathrm{p}<0.001)$ and time $\mathrm{x}$ group interactions $(\mathrm{p}<0.001)$ for oxygen uptake (VO2), carbon dioxide production (VCO2), minute ventilation (Ve), respiratory exchange ratio (RER), and REE values. MANOVA Greenhouse-Geisser univariate analysis revealed significant interactions among groups in VCO2 $(\mathrm{p}=0.003)$ and RER $(p<0.001)$ with a trend toward significance in REE $(\mathrm{p}=0.098)$. Delta analysis revealed significant differences among groups in mean change in VO2 (P: $3.8 \pm 5.2$; PWS: 15.4 \pm 5.2 ; PWS + S: $23.5 \pm 5.2 \mathrm{ml} / \mathrm{min} ; \mathrm{p}=0.03), \mathrm{VCO} 2(\mathrm{P}$ : 12.5 \pm 5.1 ; PWS: $31.8 \pm 5.1$; PWS + S: $37.7 \pm 5.1 \mathrm{ml} / \mathrm{min}$; $\mathrm{p}=0.002)$, RER (P: 0.033 \pm 0.009 ; PWS: 071 \pm 0.009 ; PWS +S: 0.071 $\pm 0.009 ; \mathrm{p}=0.005$ ), and REE (P: $0.034 \pm 0.025$; PWS: $0.095 \pm 0.025$; PWS + S: $0.132 \pm 0.025 \mathrm{kcal} / \mathrm{min}$; $\mathrm{p}=0.02$ ) with significant differences observed among the $\mathrm{P}$ group and both supplemented groups. PWS-S ingestion promoted a more prominent increase in VO2, VCO2, and REE during the initial 5-10 minutes after ingestion with differences minimizing thereafter. Area under the curve (AUC) analysis of changes from baseline revealed that PWS + S and PWS supplementation resulted in significantly greater AUC values than $P$ in VO2 (PWS+S: 1,034 \pm 584 ; PWS: 802 \pm 434 ; P: 684 \pm 376 ; $\mathrm{p}=0.01$ ); VCO2 (PWS + S: $1,372 \pm 604$; PWS: $1,151 \pm 604$; P: 634 $\pm 262 ; \mathrm{p}<0.01)$; and RER (PWS $+S: 2.79 \pm 0.89$; PWS: $2.44 \pm 0.98$; $P: 1.46 \pm 0.66 ; \mathrm{p}<0.01)$. There were no significant interaction effects for HR ( $\mathrm{p}=0.77)$, SBP $(\mathrm{p}=0.35)$, or DBP $(p=0.65)$ and there was no evidence of an increase in ECG assessed arrhythmias during the REE assessment.

\footnotetext{
* Correspondence: rkreider@hlkn.tamu.edu

Texas A\&M University, College Station, Texas, USA
} 


\section{Conclusion}

Ingesting a PWS containing beta alanine, creatine nitrate, arginine AKG, N-Acetyl Tyrosine, caffeine, and Mucuna pruriens increased resting VO2, VCO2, RER, and tended to increase REE values in comparison to a placebo. Addition of $20 \mathrm{mg}$ of synephrine to the PWS resulted in a greater increase in the metabolic response during the first 5-10 minutes after ingestion but differences were not as apparent thereafter and AUC values were not significantly different between the PWS and PWS + S groups. PWS and $\mathrm{PWS}+\mathrm{S}$ ingestion did not result in a significantly different HR or BP responses during the REE test in comparison to $P$ responses. Results indicate that ingestion of these preworkout supplements promoted modest thermogenic response and that addition of $20 \mathrm{mg}$ of synephrine to the PWC provided limited additional benefit.

\section{Acknowledgement}

Supported by Woodbolt International, Inc. (Bryan, TX)

Published: 1 December 2014

doi:10.1186/1550-2783-11-S1-P35

Cite this article as: Jung et al.: Thermogenic and hemodynamic effects of ingesting a pre-workout supplement with and without synephrine. Journal of the International Society of Sports Nutrition 2014 11(Suppl 1):P35.

Submit your next manuscript to BioMed Central and take full advantage of:

- Convenient online submission

- Thorough peer review

- No space constraints or color figure charges

- Immediate publication on acceptance

- Inclusion in PubMed, CAS, Scopus and Google Scholar

- Research which is freely available for redistribution

Submit your manuscript at www.biomedcentral.com/submit 